\title{
The EISCAT meteor-head method - a review and recent observations
}

\author{
A. Pellinen-Wannberg \\ Swedish Institute of Space Physics, Kiruna, Sweden \\ Received: 11 September 2003 - Published in Atmos. Chem. Phys. Discuss.: 4 December 2003 \\ Revised: 7 April 2004 - Accepted: 13 April 2004 - Published: 21 April 2004
}

\begin{abstract}
Since the very first meteor observations at EISCAT in December 1990, the experimental method has improved significantly. This is due to a better understanding of the phenomenon and a recent major upgrade of the EISCAT signal processing and data storage capabilities. Now the simultaneous spatial-time resolution is under $100 \mathrm{~m}$-ms class. To illuminate the meteor target for as long as possible and simultaneously get as good altitude resolution as possible, various coding techniques have been used, such as Barker codes and random codes with extremely low side lobe effects. This paper presents some background and the current view of the meteor head echo process at EISCAT as well as the observations which support this view, such as altitude distributions, dual-frequency target sizes and vector velocities. It also presents some preliminary results from recent very high resolution tristatic observations.
\end{abstract}

\section{Introduction}

Interest in meteor studies by incoherent scatter or high power large aperture (HPLA) radars has increased remarkably. There were some studies done in the 60 's at $300 \mathrm{MHz}$ by Greenhow and Watkins (1964) and at $440 \mathrm{MHz}$ by Evans $(1965,1966)$ without any follow-up for many years. EISCAT observations on the Geminid and Perseid meteor showers in 1990, 1991 and 1993 started a new era of meteor studies on HPLA radars (Pellinen-Wannberg and Wannberg, 1994, 1996; Wannberg et al., 1996; Pellinen-Wannberg et al., 1998; Westman et al., 1997). Almost simultaneously meteor observations were performed at Jicamarca (Chapin and Kudeki, 1994a, b) and at Arecibo (Zhou et al., 1995; Mathews et al., 1997; Zhou and Kelley, 1997). Even other EISCAT measurements report possible meteor echoes (Malnes

Correspondence to: A. Pellinen-Wannberg

(asta.pellinen-wannberg@irf.se) et al., 1996). EISCAT observations have continued during the 1997, 1998 and 1999 Leonids (Pellinen-Wannberg et al., 1999; Janches et al., 2002a). Recently a series of systematic tristatic dust measurements started. The new radar method shows that a great deal of new interesting physics can be extracted from the interaction between meteors and the ionosphere from the direct head echoes scattered from the meteoroids or the coma surrounding the body due to the interaction with the atmosphere, from the ionised trails left behind the meteors and from the strong sporadic layers containing metals of meteoric origin.

EISCAT, the European Incoherent Scatter radar facility comprises three radars, a tristatic $930 \mathrm{MHz}$ UHF system, a bistatic $500 \mathrm{MHz}$ ESR (EISCAT Svalbard Radar) system and a $224 \mathrm{MHz}$ VHF system. The results presented in this paper are based on observations from the two mainland radars. Both the UHF and VHF transmitters are located at Ramfjordmoen near Troms $\varnothing$, Norway $\left(69.6^{\circ} \mathrm{N}, 19.2^{\circ} \mathrm{E}\right)$. The transmitters work at peak powers close to $2 \mathrm{MW}$. The parabolic $32-\mathrm{m}$ $\mathrm{UHF}$ antenna $3 \mathrm{~dB}$ beam width is $0.6^{\circ}$, corresponding to a $1 \mathrm{~km}$ half-power beam diameter at $100 \mathrm{~km}$ range. The VHF radar has a $120 \mathrm{~m} \times 40 \mathrm{~m}$ parabolic cylinder antenna, which produces a roughly elliptical $1.2^{\circ} \times 1.7^{\circ} 3 \mathrm{~dB}$ beam, corresponding to a $2 \mathrm{~km} \times 3 \mathrm{~km}$ half-power beam width at $100 \mathrm{~km}$ range. The two remote UHF receivers are located in Kiruna, Sweden $\left(67.9^{\circ} \mathrm{N}, 20.4^{\circ} \mathrm{E}\right)$ and Sodankylä, Finland $\left(67.4^{\circ} \mathrm{N}\right.$, $\left.26.6^{\circ} \mathrm{E}\right)$.

Among the most important new results from the EISCAT radars are the detection of oblique head echoes at both UHF and VHF and a variety of their properties such as the altitude distributions and cross sections (Pellinen-Wannberg and Wannberg, 1994; Westman et al., 1997). In many cases, the same meteor has been observed simultaneously at both VHF and UHF (Wannberg et al., 1996). The interpretation of the physical character of the scattering process behind the head echoes in the VHF-UHF frequency range is based on these dual frequency observations. Meteor trail echoes have 


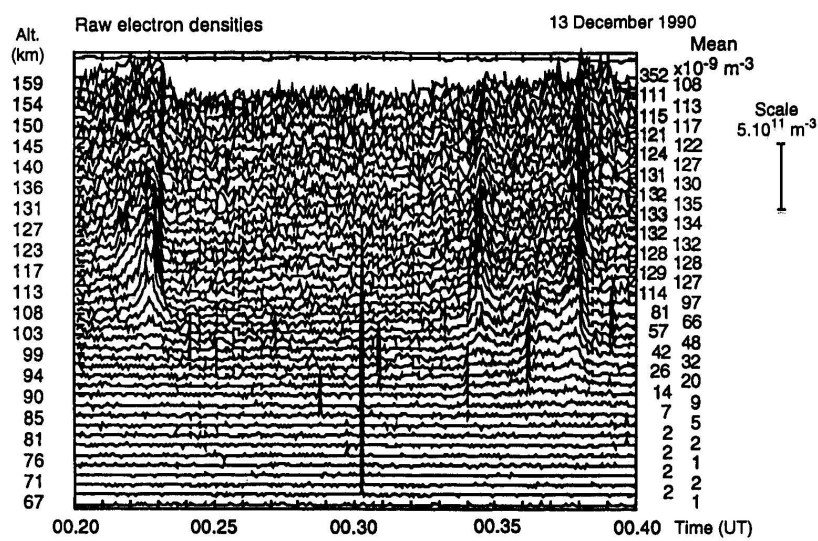

Fig. 1. EISCAT raw electron density time series versus altitude showing both meteor head echoes (sharp peaks) and weak auroral precipitation (between 00:21 and 00:23 UT and between 00:34 and 00:39 UT). (Adapted from Pellinen-Wannberg et al., 1998.)

been observed in a much larger altitude range than with traditional meteor radars. The reason is probably that at least a part of the trails is observed through other scattering mechanisms, apparently incoherent scatter (Pellinen-Wannberg and Wannberg, 1996). Using 13-baud Barker codes offers a possibility for very accurate instantaneous velocity measurements of the meteors (Wannberg et al., 1996). Using the tristatic UHF system for such measurements, the full vector velocities of the meteors passing the common tristatic measurement volume can be resolved (Pellinen-Wannberg et al., 1999), revealing whether the particle has been bound to the solar system and to a comet or if it comes from interstellar space (Janches et al., 2002a, b). The particles observed with this method are in $0.1-1.0 \mathrm{~mm}$ size range corresponding to a visual magnitude range of +10 to +4 . The meteor population that the radar observes is clearly one of much smaller particles than the optically observable population (PellinenWannberg et al., 1998).

\section{The first observations}

The first meteor head echoes observed with EISCAT were reported in Pellinen-Wannberg and Wannberg (1994). This paper and Pellinen-Wannberg et al. (1998) show how meteor head echoes are seen in raw electron time series versus altitude plots both during quiet and during weak auroral activity conditions (see Fig. 1 adapted from Pellinen-Wannberg et al., 1998). Both papers also show examples of meteor head echoes as they appear in Barker-coded raw electron density profiles. They have very strange unphysical forms, which are spread over 25 range gates. This is also the range of the Barker-code ambiguity function. As the meteor targets have large Doppler shifts, the matched-filter pulse compression fails and the decoded received signals get odd-looking and rapidly varying forms over the 25 gates. However, each

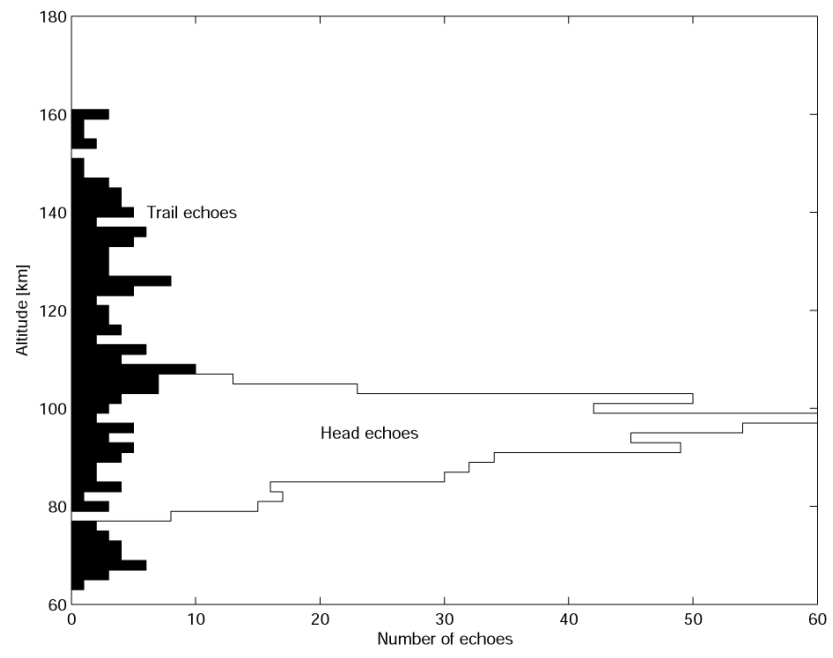

Fig. 2. Altitude distributions of the meteor head and trail echoes recorded during the December 1990 and 1991 observing periods.

individual form corresponds to a specific Doppler shift. Thus a component of the meteoroid velocity can be estimated.

Figure 2 shows the altitude distributions of the head and trail echoes observed during the first meteor campaigns at EISCAT. The classification of the echoes was done as follows. The trail echoes cause longer lasting signals with very small Doppler shifts if any at all, while the head echoes are very transient (milliseconds) and have Doppler shifts of 3$80 \mathrm{~km} / \mathrm{s}$. While the EISCAT trail echoes are distributed over the whole observing range, the head echoes are limited between 75 and $110 \mathrm{~km}$, reminiscent of classical meteor radar trail altitude distributions. However, the reason for the upper cut-off in the head echo distribution cannot be the same as for meteor radar trail distributions. Section 4 below discusses the scattering process that causes the head echoes and explains the significance of the upper cut-off.

\section{What is a HPLA radar?}

HPLA stands for High Power and Large Aperture for a radar facility. Most of these, such as Arecibo, Millstone Hill, Sondrestrom and EISCAT, have been designed to observe (at VHF and/or UHF) the very weak Thomson scattering from nominally free electrons through the ionosphere up to $2000 \mathrm{~km}$ altitude. The common feature for these instruments are the high power in megawatt class, the large signal collecting area of thousands of square meters and very high signal processing and data storage capabilities. The technical differences between the meteor radars and HPLA radars also lead to differences in the observing processes and parameters.

The frequency range for meteor radars extends from slightly above the maximum ionospheric plasma frequency, where meteor trails first become observable, to the value corresponding to the situation where the wavelength is of the 
same order as the trail radius and the trail becomes invisible for the radar due to destructive interference. The frequency range for incoherent scatter radars is chosen so that the effect of the ions can be seen in the scatter spectrum. This occurs when the exploring wavelength is much larger than the Debye length in the ionosphere. This parameter is less than $1 \mathrm{~cm}$ at $100 \mathrm{~km}$ and about $6 \mathrm{~cm}$ at $2000 \mathrm{~km}$ altitude (Evans, 1969). Thus the radars dedicated for this process operate from $40 \mathrm{MHz}$ to $1.3 \mathrm{GHz}$. Also some military radars and radar telescopes with large apertures work at these frequencies and can be classified as HPLA radars.

The ionisation caused by meteors exceeds the background ionospheric levels locally along the trail and diffuses away only after a time in the order of seconds. Thus the process is observable with standard Yagi antennas with quite low power if the geometry and the frequency are right. On the other hand, the cross section for the Thomson scatter from ionospheric electrons is very small; thus very large collecting areas for the signals combined with high transmitter power are needed. The antenna geometry together with the radar frequency define the beam width. For classical meteor radars, the opening angle is usually tens of degrees and can approach $\pi$ steradians, if the intention is to study sporadic meteors. The HPLA radars usually have very narrow beams due to their very small wavelength to diameter quotient.

The velocity of the meteoroids observed with meteor radars is estimated with the Fresnel diffraction method (McKinley, 1961). At EISCAT, velocities have been estimated both from Doppler shifts derived from the Barkercode ambiguity function distortion (Pellinen-Wannberg and Wannberg, 1994) and time-of-flight estimates (Wannberg et al., 1996).

Most of the echoes observed with meteor radars are the beam-perpendicular trail echoes, even though head echoes were occasionally observed with the most powerful radars. At EISCAT UHF about $73 \%$ of the echoes were transient highly Doppler-shifted head echoes, while the rest could be classified as longer lasting trail echoes.

Meteor radars can be optimised for shower meteor observations due to the beam-perpendicularity requirement. If the radar beam is not too broad and it is oriented perpendicular to the radiant direction of the meteor shower, only meteors in the radiant plane can be observed. Most of them are then probably related to the shower. Observations at EISCAT during Geminids 1990 and 1991, Perseids 1993 and Leonids 1997 and 1998 do not show any apparent flux increases during the shower maxima (Pellinen-Wannberg et al., 1998; Janches et al., 2002a). The reason for this is probably that the radar observation volumes are very small, about $1 \mathrm{~km}$ in diameter and 150-450 $\mathrm{m}$ high for EISCAT UHF. The probability of catching a shower meteor is thus very small, while it is much larger for the numerous sporadic very small meteoroids background population.

Some advantages of the classical meteor radars as instruments are that they are small, simple and cheap both in con- struction and in use. They can be deployed in areas of interest quite quickly and they can be run for long periods. HPLA radars are multi-million dollar projects and require years of planning. Thus there are just some 10 such facilities in the world, located at strategic places adapted to their primary application, such as auroral zone research (EISCAT, ESR, Sondrestrom) or along a magnetic meridian (Sondrestrom, Millstone, Arecibo, Jicamarca). These instruments are expensive to operate and most often cannot be run continuously. There is strong competition between the different user groups, astronomers, space and atmospheric scientists, for the operation times.

To summarize, there are three essential technical differences between the meteor and HPLA radars, the beam width, the power and the frequency range. The first two contribute to more than three orders of magnitude higher power density at $100 \mathrm{~km}$ range for HPLA radars. In general, radio waves reflect from density gradients or densities enhanced above the background level in the ionosphere. Thus more meteors are observed at lower frequencies in the meteor radar as well as HPLA radar frequency range. Traditionally UHF and VHF have not been considered for meteor studies. However, for the powerful HPLA radars the sensitivity takes over and the relatively faint head echoes, which were rarely observed with meteor radars, become the principal targets for this method. Trail echoes are relatively rare at HPLA radar UHF for two reasons. Firstly, a very few trails can be perpendicular to the narrow beam of one degree or less. Secondly, destructive interference makes the expanding trails invisible very quickly due to the monitoring submeter wavelengths.

\section{Overdense head echo scattering process}

The foundation for the overdense head echo scattering model for EISCAT was presented by Wannberg et al. (1996) based on EISCAT VHF/UHF dual frequency observations on estimated target sizes and head echo altitude distributions, and has been further reported by Westman et al. (1997, 2004). The reported high vector velocities from the tristatic EISCAT observations (Janches et al., 2002a) also support the model requiring high-energy meteoroid-atmosphere interactions.

In the first approximation the model just discusses the plasma interaction in the immediate vicinity of the meteoroid. The limit for the target is the limit of the overdense ionisation, which is a few centimetres in radius and depending on the observing frequency. Thus there is also enhanced ionisation outside this limit. The ionisation is controlled by the ionising process of the atoms and molecules on the meteoroid surface, in the atmosphere and the compression of the ionised volume due to the penetration of the meteoroid into the deeper and denser atmosphere. The produced ionisation corresponds to the expanding line density that is left behind the meteoroid. 


\section{The appearance of overdense head echo condition for EISCAT observation}

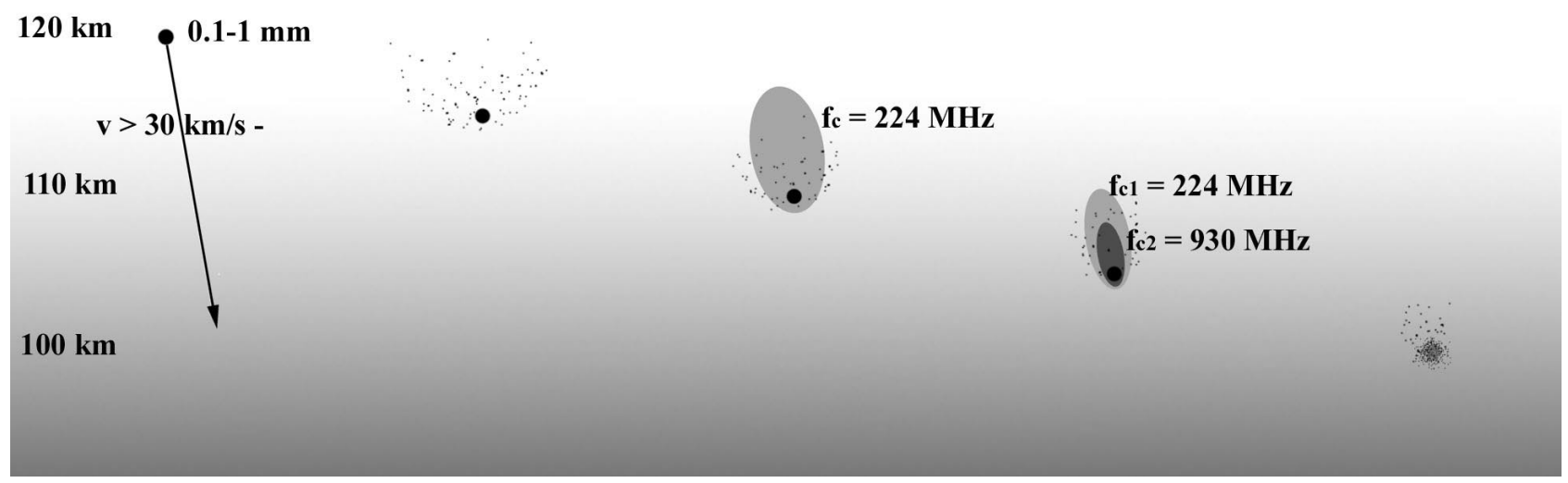

Fig. 3. The meteor head echo appears first at the VHF as the target reaches the critical density and a few kilometres lower down at the UHF as the target plasma is compressed further to the corresponding critical density.

Head echo altitude distributions from simultaneous UHF and VHF observations in August 1993 show a clear difference in the altitudes (Westman et al., 2004). A parameter to compare the altitude distributions, a "cutoff height" was defined, (i.e. the altitude below which $90 \%$ of the head echoes are observed). The parameter is related to the upper edge of the distribution since it is there where the essential interaction for the ionising model occurs. At the lower edge other processes, such as ablation, might contribute. The cutoff height for the VHF is $109.8 \pm 0.3 \mathrm{~km}$ and for the UHF it is $104.0 \pm 0.2 \mathrm{~km}$. A careful analysis is done to show that biases due to different UHF and VHF beam widths are $10 \%$ at most of the observed $5.8 \mathrm{~km}$ cutoff height differences. Thus the differences in the altitude distributions are real. However they are difficult to compare between different radars due to different frequencies, sensitivity and differing atmospheric conditions. Summer/winter observations at EISCAT have shown that the cutoff heights can vary between 2 and $4 \mathrm{~km}$. Comparisons with atmospheric models show that the cutoff height occurs at a constant atmospheric mean free path value for a given wavelength. Recently Close et al. (2004) have confirmed with their theoretical calculations that the VHF distribution should be slightly higher up than the UHF distribution.

Head echo targets seem to be larger for VHF than even for simultaneous UHF meteors, indicating that the shorter wavelength UHF penetrates deeper into the ionised target. The target sizes can be estimated by assuming that the signal power is proportional to the target size. The radar beam power density follows normal distribution. Even the scattered head echo strength follows the distribution as the meteor is passing the beam. With the present EISCAT one cannot say how far from the beam centre the meteor goes. Thus all observed meteors are assumed to pass the middle of the beam, which leads to an underestimation of the sizes of the particles, which pass beside it. The signal power from the small meteor target is compared to the signal power of the whole observing volume which is the $500 \mathrm{~m}$ radius cylinder of the EISCAT UHF radar beam and $2 \mathrm{~km} \times 3 \mathrm{~km}$ elliptic cylinder for the VHF beam at $100 \mathrm{~km}$ range. The target sizes are obtained by assuming that the equivalent number of scattering electrons is compressed to a ball or coma of the size where they would reach the critical frequency corresponding to the monitoring frequency. The radii for UHF targets are $1-2 \mathrm{~cm}$ and for VHF $2.7-4.7 \mathrm{~cm}$ (Wannberg et al., 1996; Westman et al., 2004).

Figure 3 shows a schematic view on the meteoroidatmosphere interaction process along the meteoroid path when it is penetrating to the layers of increasing density in the atmosphere based on the observations reported above. The VHF echo appears when the plasma generated in the interaction process reaches the $224 \mathrm{MHz}$ critical density of $6 \times 10^{14} \mathrm{~m}^{-3}$. A few kilometres further down, the plasma density increases partly due to further ionisation and partly due to the compression of the interaction volume, so that even the critical frequency corresponding to EISCAT $931 \mathrm{MHz}, 1 \times 10^{16} \mathrm{~m}^{-3}$, is reached. At the same time the VHF echo is still observed. In dual frequency observations of a common volume by EISCAT, every UHF meteor is also seen in VHF.

\section{Velocities}

The velocity is one of the basic parameters to estimate when observing meteors by any method. To be observed by meteor radar, the meteor path must be close to perpendicular to the radar beam due to the scattering process. The velocity estimated from the Fresnel diffraction pattern is thus a parameter comparable to other observations. With monostatic 
HPLA radars only the component along the radar beam is obtained either by time-of-flight or by the Doppler method. It is important to keep in mind the mathematical fact that knowing one arbitrary velocity component does not give you more than a lower limit of the total vector velocity.

The tristatic EISCAT UHF can observe the true vector velocities for meteoroids that enter the common observing volume. The rates are low, but the results are very accurate. A set of tristatic meteors was analysed by Janches et al. (2002a). One of these meteors has a downward component of $3.9 \mathrm{~km} / \mathrm{s}$ while its vector velocity is $72.7 \mathrm{~km} / \mathrm{s}$. This meteor is in fact of interstellar origin (Janches et al., 2002b). Thus one must be careful when using monostatic velocity observations without any knowledge of the meteor path direction.

In general the observed vector velocities are high. The velocity values of the ten tristatic EISCAT meteors varied between 38.7 and $85.7 \mathrm{~km} / \mathrm{s}$, while the mean value was $64.7 \mathrm{~km} / \mathrm{s}$. Close et al. (2002a) report from the ALTAIR radar absolute velocities averaging $52 \mathrm{~km} / \mathrm{s}$ at VHF and $65 \mathrm{~km} / \mathrm{s}$ at UHF. Close et al. (2002b) report values down to $30 \mathrm{~km} / \mathrm{s}$, but notice an absence of $20 \mathrm{~km} / \mathrm{s}$ sporadics apparently due to the limiting capability of the radar. Observing lower velocities is not impossible, but probably a larger particle is needed. The observed high velocities indicate that a high-energy interaction is needed for the meteoroid to become observable through the head echo process. This is in agreement with the overdense head echo scattering model. Thus one must remember that just the high velocity fraction of the meteoroid population can be observed with this method.

\section{New observations}

The EISCAT mainland radars UHF and VHF have recently (2000) gone through a comprehensive upgrading. There are new powerful klystrons and a receiver cooling system installed at Troms $\varnothing$ and new real-time signal processing systems have been installed at all sites. Thus the sensitivity of the upgraded radars can be estimated to have increased by a factor of 10 compared to the earlier meteor observation modes.

In the early tristatic EISCAT observations in 1997 to 1999 the Troms $\varnothing$ antenna was pointing vertically and the remotes were pointing towards the radar beam at about $105 \mathrm{~km}$ altitude. Since the distance from the Sodankylä site is quite large to Troms $\emptyset$ (about $400 \mathrm{~km}$ ), the Sodankylä receiver often failed to see the meteors that were observed with the two other sites. Only the strongest ones were seen with all three antennas, resulting in 10 tristatics during about $40 \mathrm{~h}$.

To optimise the tristatic EISCAT observations, contributing factors such as the distances to the common volume from the three receiving sites, the polarisation factors and the size of the common volume were studied. A point slightly north of the middle point between Troms $\varnothing$ and Sodankylä was cho-

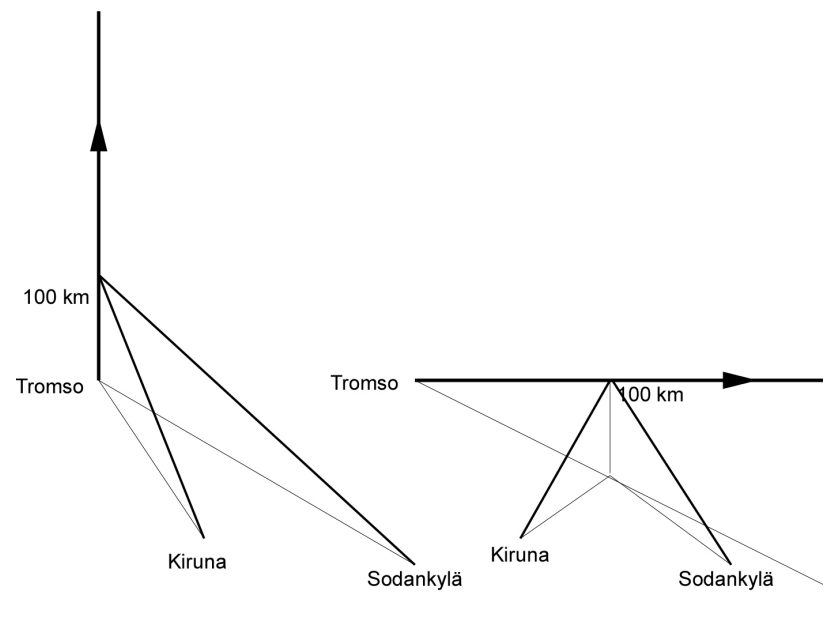

(a) old configuration

(b) new configuration

Fig. 4. The EISCAT tristatic measurement geometry. During the first experiments the Troms $\emptyset$ beam was vertical and the remotes where pointing to it at about $105 \mathrm{~km}$ altitude (a). (b) shows the optimised geometry to get highest possible tristatic rates.

sen in the EISCAT "tetrahedron" configuration. This was best for the polarization factor. In addition, the common volume increased in size due to the longer range to the transmitter. Figure 4 shows shows both the old geometry (a) and the new measurement configuration (b). During the vernal equinox in 2002, 33 tristatic events were observed during a 24-h period, showing a good increase of event rates.

The meteoroid velocities have been estimated from the distortion of the Barker-code ambiguity functions as described in Sect. 2. Due to improved signal processing equipment, better and more advanced coding techniques are now available. The latest observations have been run with a 32-bit pseudo random code with extremely low side lobes.

Figure 5 shows an example of a tristatic observation from March 2002. The meteor passing the radar beam is observed from three different directions. The upper panel data is recorded with the Troms $\varnothing$ receiver, thus k-vector component is in the radar beam direction. The lower panels show data from Kiruna and Sodankylä. The k-vectors in this case are defined as the unit vectors pointing in the direction of the bisector defined by the Troms $\emptyset$ transmitter beam and the corresponding receiver antenna pointing. As the velocity components are measured in these three directions, the velocity vector can be converted and given in an ordinary orthogonal local northward, eastward and downward coordinate system.

The meteor passes the radar beam in about 10 milliseconds as seen in the upper panel. Each of the 12 peaks corresponds to one 32-bit code sequence. In all the three observing directions the gaussian power density form of the radar beam is easily recognised. An independent velocity estimate can be made for each code sequence in all three directions. Thus the vector velocities in about 12 steps with some $0.8 \mathrm{~ms}$ intervals 


\section{EISCAT tristatic meteor observation 2002-03-20 07:16:15 UT}

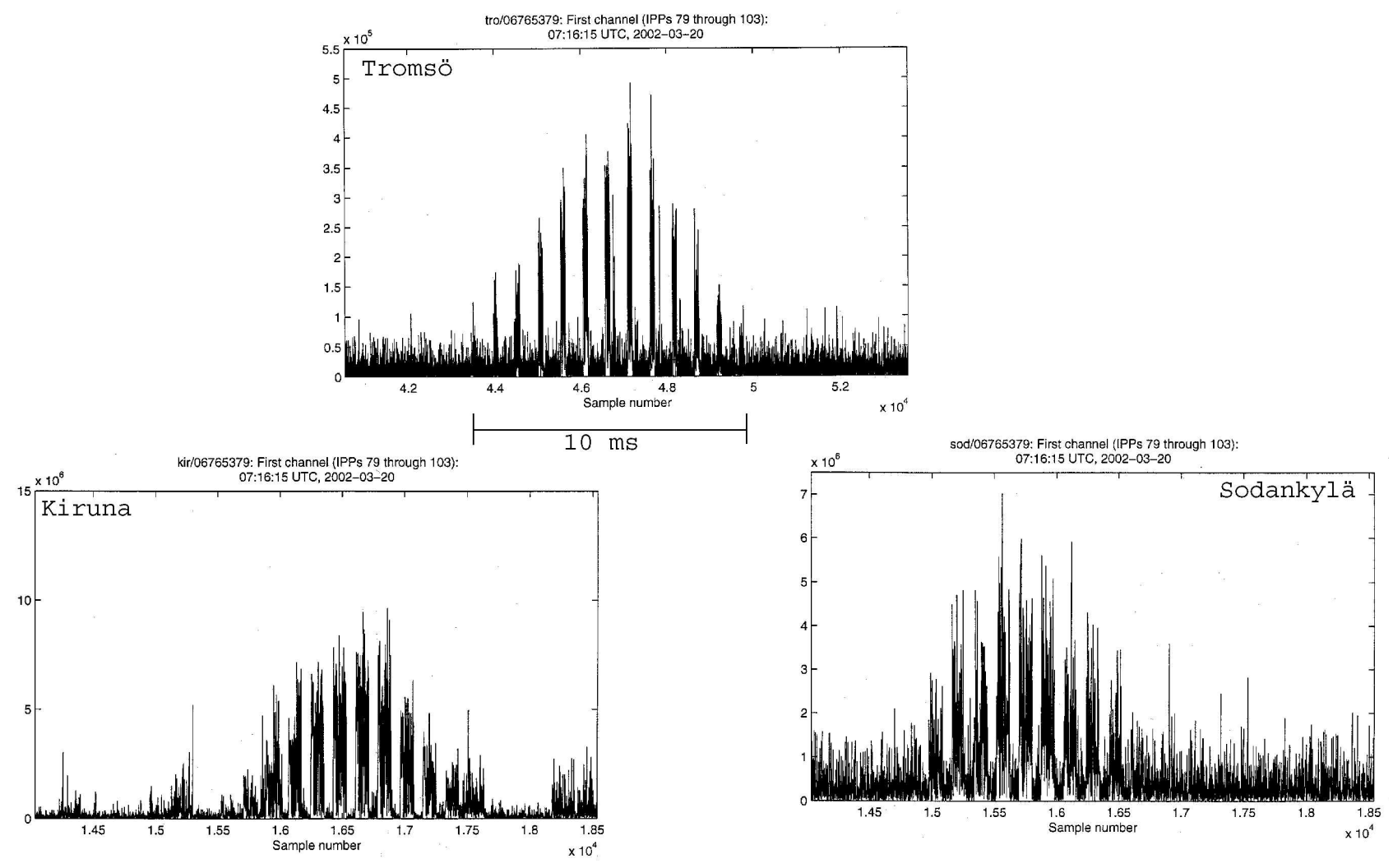

Fig. 5. Tristatic meteor observation with the EISCAT UHF radar. The vertical axes show in arbitrary units the returned power in the scattering process from the meteor head. The meteor is seen from three different directions (Kiruna, Troms $\emptyset$ and Sodankylä) when it passes the radar beam.

can be estimated as well as the vector retardation of the meteoroid if the velocity decreases when passing the beam.

\section{Conclusions}

After 13 years of meteor observations of meteor head echoes at EISCAT, one can conclude that this method of using HPLA radars for meteor studies is established. Studies are run on most facilities in the world and many interesting new results have been published in some 50 papers so far. There are a few contradictions in interpretations from some of the facilities, e.g. interpretation of head echoes from EISCAT and Arecibo (Wannberg et al., 1996; Mathews et al., 1997). However, it looks as though an explanation can be found in the size of the instruments.

Whatever the head echo scattering mechanism is, the method is superior for studying in detail many aspects of the meteoroid impact process in the atmosphere. Vector velocities and retardations, angle dependence of the scattering process as well as target sizes can be studied from the data shown in Fig. 5. Variations of many background parame- ters such as electron density, electron and ion temperatures, some ion-composition etc can be measured in a range of tens of kilometres around the typical meteor observing altitudes if the HPLA radars are run simultaneously when monitoring meteors in an ordinary ionospheric incoherent scatter mode. This can be used to study the connection between the meteor input and sporadic E-layers as well as general ionisation enhancement induced by meteor showers.

EISCAT has two radars located at the same site in Troms $\varnothing$ - the $930 \mathrm{MHz}$ UHF and the $224 \mathrm{MHz}$ VHF. These can observe the same meteors at different wavelengths and achieve deeper understanding of the true scattering process. Even the location of EISCAT at the high latitudes offers some exciting challenges. High up on the Earth from the solar system point of view, EISCAT can observe the component of the extraterrestrial dust cloud moving off the ecliptical plane. 
Acknowledgements. I wish to thank G. Wannberg, A. Westman and D. Janches for their contribution to results reviewed in this paper. I gratefully acknowledge the EISCAT staff for their assistance during the experiments. The EISCAT Scientific Association is supported by the Centre National de la Recherche Scientifique of France, the Max-Planck-Gesellschaft of Germany, the Particle Physics and Astronomy Research Council of the United Kingdom, Norges Almenvitenskapelige Forskningsråd of Norway, Vetenskapsrådet of Sweden, Suomen Akatemia of Finland, and the National Institute of Polar Research of Japan. The visit to the Radar Meteor Workshop at Arecibo Observatory was supported by European Office of Aerospace Research and Development (EOARD) WOS grant.

Edited by: D. Janches

\section{References}

Chapin, E. and Kudeki, E.: Radar interferometric studies of longduration meteor echoes observed at Jicamarca, J. Geophys. Res., 99, 8937, 1994a.

Chapin, E. and Kudeki, E.: Plasma wave excitation on meteor trails in the equatorial electrojet, Geophys. Res. Let., 21, 2433, 1994b.

Close, S., Oppenheim, M., Hunt, S., and Duryd, L.: Scattering characteristics of high-resolution meteor head echoes detected at multiple frequencies, J. Geophys. Res., 107, (A10), 1295, doi:10.1029/2002JA009253, 2002a.

Close, S., Hunt, S., Minardi, M., and McKeen, F.: Characterization of Leonid meteor head echo data collected using the VHF/UHF Advanced Research Projects Agency Long-Range and Tracking Radar, Radio Sci., 37, (1), doi:10.1029/2000RS002602, 2002b.

Close, S., Oppenheim, M., Hunt, S., and Coster, A.: A technique for calculating meteor plasma density and meteoroid mass from radar head echo scattering, Icarus, 168, 43-52, 2004.

Evans, J. V.: Radio-echo studies of meteors at 68-centimeter wavelength, J. Geophys. Res., 70, 5395-5416, 1965.

Evans, J. V.: Radar observations of meteor deceleration, J. Geophys. Res., 71, 171-188, 1966.

Evans, J. V.: Theory and practice of ionosphere study by Thomson scatter radar, Proc. IEEE, 57, 496, 1969.

Greenhow, J. S. and Watkins, C. D.: The characteristics of meteor trails observed at a frequency of $300 \mathrm{Mc} / \mathrm{s}$, J. Atmos. Terr. Phys., 26, 539-558, 1964.

Janches, D., Pellinen-Wannberg, A., Wannberg, G., Westman, A., Häggström, I., and Meisel, D. D.: Tristatic observations of meteors using the $930 \mathrm{MHz}$ EISCAT radar system, J. Geophys. Res., 107, (A11), 1389, doi:10.1029/2001JA009205, 2002a.
Janches, D., Pellinen-Wannberg, A., Wannberg, G., Meisel, D. D., Westman, A., and Häggström, I.: The tristatic $930 \mathrm{MHz}$ EISCAT radar system: a unique tool for meteor/dust studies, URSI GA Proceedings, 2002b.

Mathews, J. D., Hunter, K. P., Meisel, D. D., Getman, V. S., and Zhou, Q.: Very High Resolution Studies of Micrometeors Using the Arecibo $430 \mathrm{MHz}$ Radar, Icarus, 126, 157, 1997.

Malnes, E., Bjørnå, N., and Hansen, T. L.: Anomalous echoes observed with the EISCAT UHF radar at $100-\mathrm{km}$ altitude, Ann. Geophys., 14, 1328-1342, 1996.

McKinley, D. W. R.: Meteor science and engineering, McGrawHill, 1961.

Pellinen-Wannberg, A. and Wannberg, G.: Meteor observations with the EISCAT UHF incoherent scatter radar, J. Geophys. Res. 99, 11 379-11390, 1994.

Pellinen-Wannberg, A. and Wannberg, G.: Enhanced ion-acoustic echoes from meteor trails, J. Atmos. Terr. Phys., 58, 1-4, 495506, 1996.

Pellinen-Wannberg, A., Westman, A., Wannberg, G., and Kaila, K.: Meteor fluxes and visual magnitudes from EISCAT radar event rates: a comparison with cross section based magnitude estimates and optical data, Ann. Geophys., 16, 1475-1485, 1998.

Pellinen-Wannberg, A., Westman, A., and Wannberg, G.: A threedimensional meteor head echo Doppler shift method for the EISCAT UHF radar, Meteoroids 1998 proceedings, Astron. Inst., Slovak Acad. Sci., 83-86, 1999.

Wannberg, G., Pellinen-Wannberg, A., and Westman, A.: An ambiguity-function-based method for analysis of Doppler decompressed radar signals applied to EISCAT measurements of oblique UHF-VHF meteor echoes, Radio Science, 31, 497-518, 1996.

Westman, A., Wannberg, G., and Pellinen-Wannberg, A.: Meteor head echo height effect observed by the European Incoherent Scatter UHF and VHF radars, in Assar Westman's Ph.D. thesis, IRF Scientific Report 246, 1997.

Westman, A., Wannberg, G., and Pellinen-Wannberg, A.: Meteor head echo height distributions and the meteor impact mechanism observed with the EISCAT HPLA UHF and VHF radars, Ann. Geophys., 22, 1-10, 2004.

Zhou, Q., Tepley, C. A., and Sulzer, M. P.: Meteor Observations by the Arecibo $430 \mathrm{MHz}$ Incoherent Scatter Radar, I. Results from Time-Integrated Observations, J. Atmos. Terr. Phys., 57, 421, 1995.

Zhou, Q. and Kelley, M. C.: Meteor Observation by the Arecibo $430 \mathrm{MHz}$ ISR II. Results from Time-Resolved Observations, J. Atmos. Terr. Phys., 59, 513-521, 1997. 